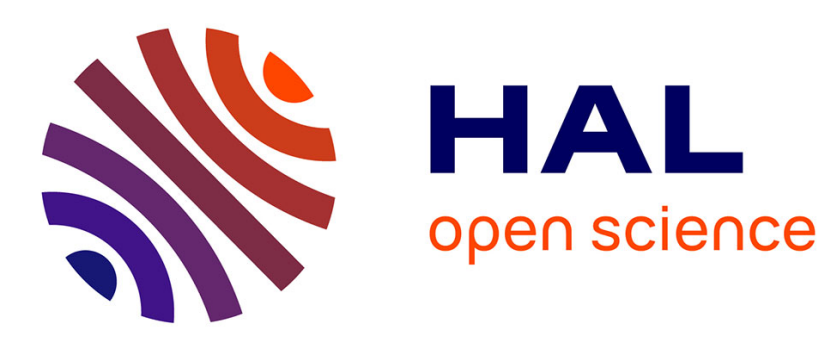

\title{
Semi-analytical study of 3 kinds of axial flux PM actuator
}

J Jennane, N. Fadli, Jean-Frederic Charpentier, Javier Rios Quesada

\section{To cite this version:}

J Jennane, N. Fadli, Jean-Frederic Charpentier, Javier Rios Quesada. Semi-analytical study of 3 kinds of axial flux PM actuator. International Journal of Applied Electromagnetics and Mechanics, 2004, 19 (1-4), pp.299-302. hal-01208388

\section{HAL Id: hal-01208388 \\ https://hal.science/hal-01208388}

Submitted on 2 Oct 2015

HAL is a multi-disciplinary open access archive for the deposit and dissemination of scientific research documents, whether they are published or not. The documents may come from teaching and research institutions in France or abroad, or from public or private research centers.
L'archive ouverte pluridisciplinaire HAL, est destinée au dépôt et à la diffusion de documents scientifiques de niveau recherche, publiés ou non, émanant des établissements d'enseignement et de recherche français ou étrangers, des laboratoires publics ou privés. 


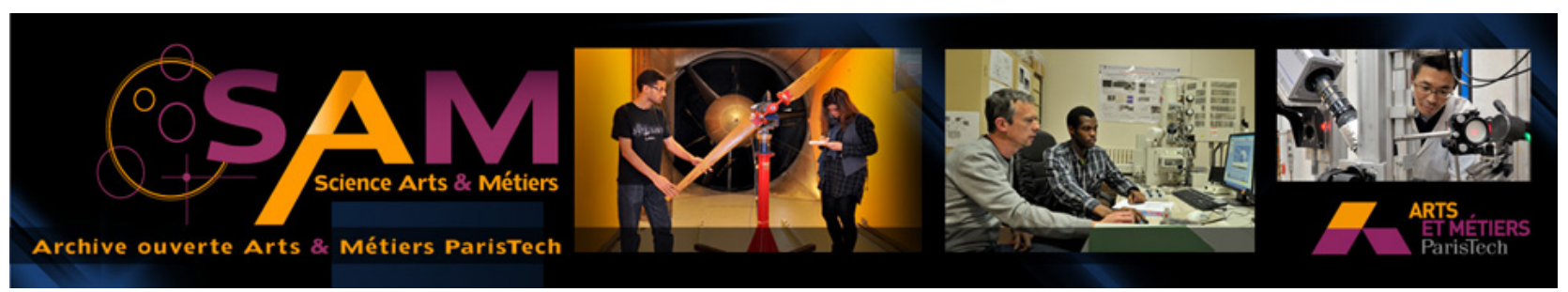

\section{Science Arts \& Métiers (SAM)}

is an open access repository that collects the work of Arts et Métiers ParisTech researchers and makes it freely available over the web where possible.

This is an author-deposited version published in: http://sam.ensam.eu

Handle ID: .http://hdl.handle.net/10985/10308

\section{To cite this version :}

J JENNANE, N. FADLI, Jean-Frederic CHARPENTIER, Javier RIOS QUESADA - Semi-analytical study of 3 kinds of axial flux PM actuator - International Journal of applied electromagnetics and mechanics - Vol. 19, n¹-4, p.299-302 - 2004 


\title{
Semi-analytical study of 3 kinds of axial flux PM actuator
}

\author{
J. Jennane ${ }^{\mathrm{b}}$, N. Fadli ${ }^{\mathrm{b}}$, J.-F. Charpentier ${ }^{\mathrm{a}, *}$ and J. Ríos Quesada ${ }^{\mathrm{a}}$ \\ IRENav Ecole Navale BP 60029240 Brest Armees, France \\ Tel.: +33 298233869; Fax: +33 298233857; E-mail: \{charpentier, rios\}@ecole-navale.fr \\ ENSEM BP8118 OASIS Casablanca, Morocco
}

Abstract. This paper deals with the study of discoidal Permanent Magnet machines using a method of field calculation based on the magnetic charges theory. This fast calculation method enables a systematic study of these devices. The presented method has been validated by a comparison with the classical FE method.

Three kinds of discoidal machines are studied and compared. The first is a classical machine with axially magnetized magnet with iron stator and rotor cores. The second and third use simple Halbach array configurations for the magnets with iron and ronless rotor core. This study illustrates the interest of the Halbach structures for this type of device.

Keywords: Axial flux, permanent magnet, analytical study

\section{Introduction}

Axial flux Permanent Magnet discoidal actuators are particularly useful because they have a very small axial length. They can be used in a lot of applications where compacity is required as high speed generators, naval propulsion drive and automotive applications [1-3]. These devices are now easier to build using iron resin composite for the soft iron cores.

For the same stator geometry, current density and specific electric loading, the performances of such a machine are mainly related to the induction level created by the magnets in the air-gap.

The classic way to study this type of machine is the 3D Finite Element method (3D FEM) which allows the field calculation in the structure. However, this solution is very cumbersome in terms of complexity and calculation time and very sensitive to the mesh quality. This method is therefore very difficult to use in a systematic design process. In this paper, a semi analytical method based on the magnetic charges theory [4] is used to calculate the induction in the device air gap. This method allows a very fast calculation of the main performances of 3 kinds of axial flux discoidal machines.

One classical structure (rotor with axial magnets) and two original structures (Halbach array with and without iron cores) of axial flux PM machines are studied using this way of calculation. These structures are compared for the same set of dimensions and for several number of pairs of poles.

The calculation results are validated by a comparison with those obtained using a classic nodal Finite Element method. 


\section{क्र}

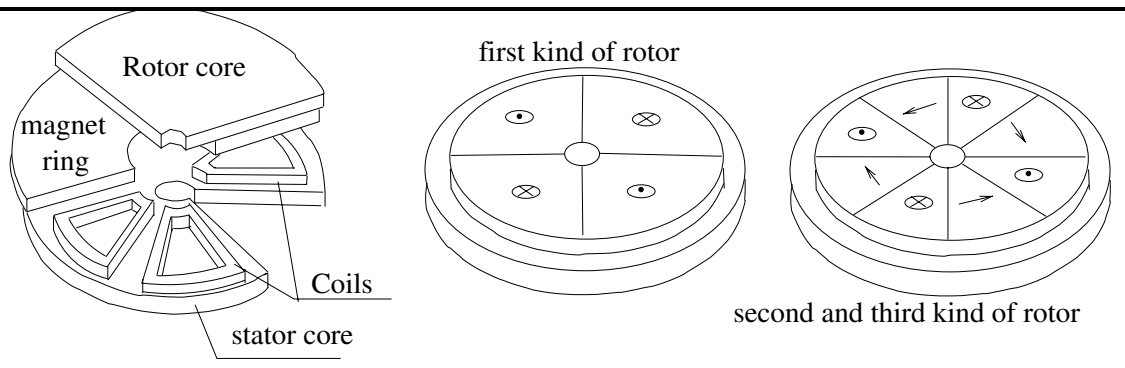

Fig. 1. Description of the structures.

\section{Machines description}

On the studied machines, the stator coils are attached to an iron discoidal core. The rotor is made with a cylindrical magnet ring fixed on a rotor core.

Three kinds of machines with three different rotor geometries are studied. In the first type of structure the magnet ring consists of alternated axially magnetized magnets (classic structure). In the second and third structures the magnet ring consists of axially and tangentially magnetized magnets fixed on the rotor core. These magnets form a simple Halbach Array [5,6].

In the first and second cases, the rotor has an iron core. In the third case, the rotor has an ironless core. This third configuration is advantageous when a very low inertia is required. Figure 1 shows the geometry of the 3 structures for a 4 poles device.

\section{Calculation method}

According to the magnetic charges theory, an uniformly magnetized magnet in free space can be represented by portions of charged surfaces. The charge density in each face of the magnet is:

$$
\sigma=\vec{J} \cdot \vec{n}
$$

Thus, an axially magnetized magnet can be represented by two charged horizontal disk sectors.

A tangentially magnetized magnet can be considered as two vertical rectangular charged planes. The influence of the stator and rotor iron cores is taken into account. If we consider that the iron core material has a very high permeability, the iron core inner surfaces can be considered as scalar equipotentials. Thus the field in the air gap can be calculated as the sum of the contributions of the charged planes representing the magnets and their mirrored images in the iron core surfaces. For an ironless rotor core with an iron stator core, only one image by plane should be taken into account. For an iron rotor core with an iron stator core, an infinite number of images should be taken into account for each magnet plane. These two configurations are shown in Fig. 2.

The induction created by a charged portion of plane $S$ (rectangular or discoidal) in a point in the structure air gap $P$ is:

$$
\overrightarrow{B_{P}}=\iint_{S} \frac{\sigma}{4 \pi} \frac{\overrightarrow{P_{S} P}}{{\overline{P_{S} P}}^{3}} d S
$$

Where $P_{S}$ is an integration point in the charged surface. This formula can be calculated analytically for rectangular planes [4] (tangential magnets). For discoidal charged surfaces (axial magnets) the solution bf the equation can be computed using a numerical integration method [7]. 

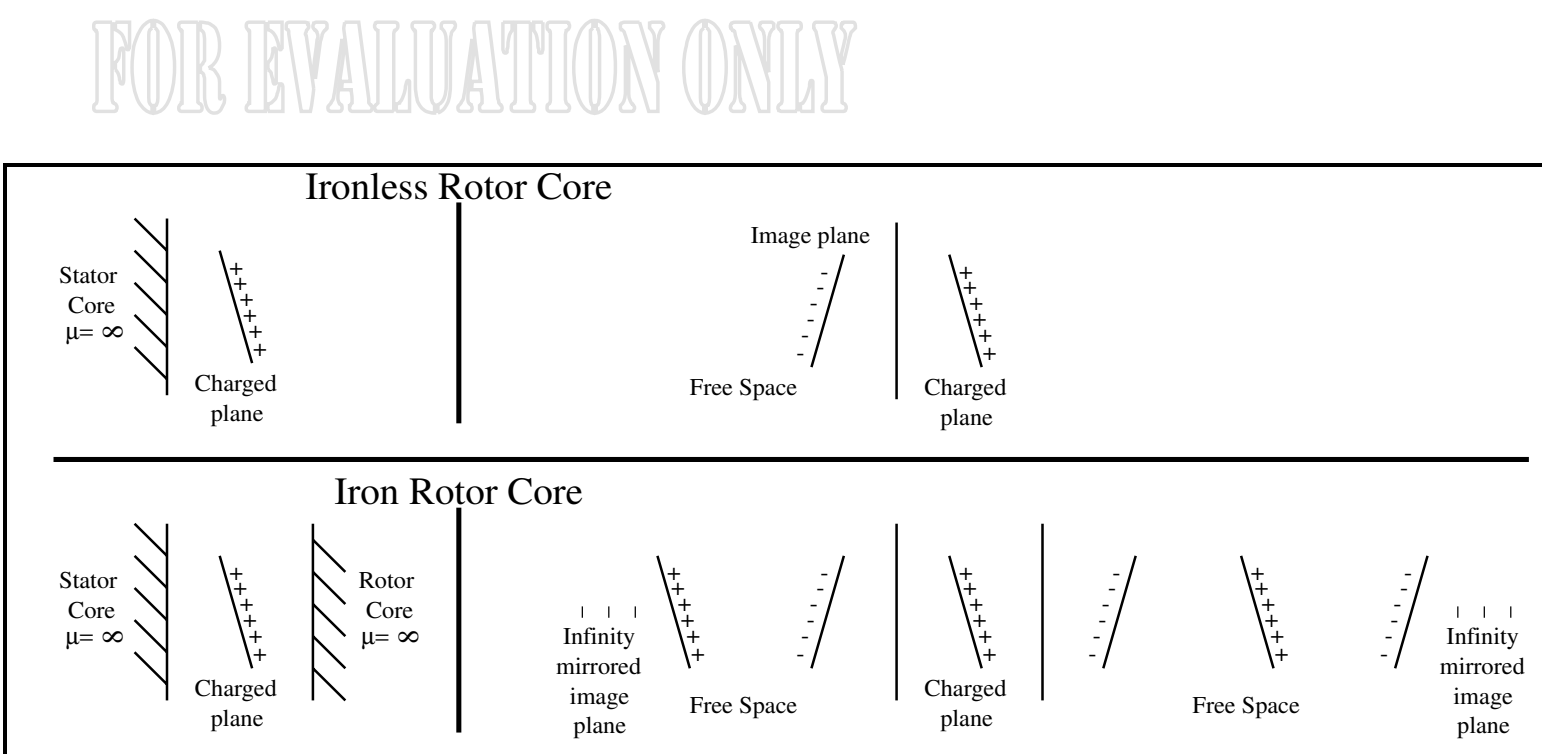

Fig. 2. Image theory apllicated to an ironless core rotor and an iron rotor.
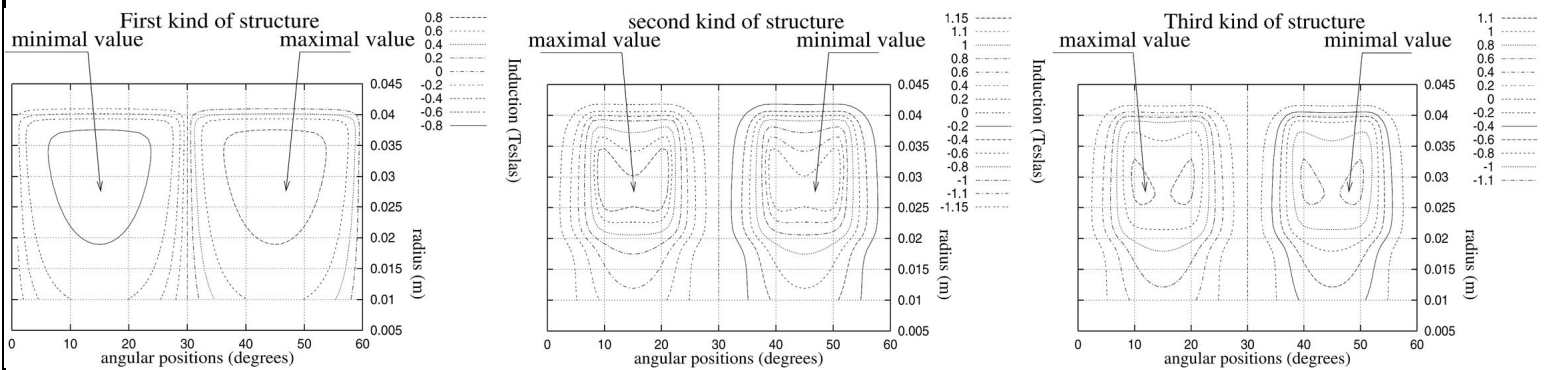

Fig. 3. Isovalues of the induction on the surface of stator for the three types of structure (6 pairs of poles).

\section{Simulation results}

All the presented structures correspond to the same set of main geometric dimensions:

- The inner and outer radii of the magnet ring, $r_{i n}$ and $r_{e x}$, are equal to 2 and $4 \mathrm{~cm}$ respectively.

- The magnet ring thickness is $1 \mathrm{~cm}$ and magnetisation of the magnets is $1 \mathrm{~T}$.

- The air gap value is $1 \mathrm{~mm}$.

As an example, the axial induction in the stator core surface for all types of machine is calculated for the same number of pairs of poles: $p=6$. The isovalues of the axial induction are given in Fig. 3 as functions of the radius and the angular position.

It can be noticed that the maximum value of the induction is greater than the magnet magnetisation in the second and third cases. This phenomenon is due to the particular disposition of the magnets (Halbach Array).

In Fig. 4, the first graph shows the average induction created by the magnets at the stator inner surface in front of the center of a rotor pole $\left(\mathrm{r} \in\left[r_{i n}, r_{e x}\right]\right.$ and $\left.\theta=\pi /(2 p)\right)$ as a function of number of pole pairs. This study shows that for a given number of pole pairs the average induction in the second and third structure reaches a maximum value which is greater than the value of induction obtained with the first kind of structure. It can also be noticed that this value is bigger than the magnet magnetization. These values are related to the global performance in terms of torque of these actuators. 


\section{6}
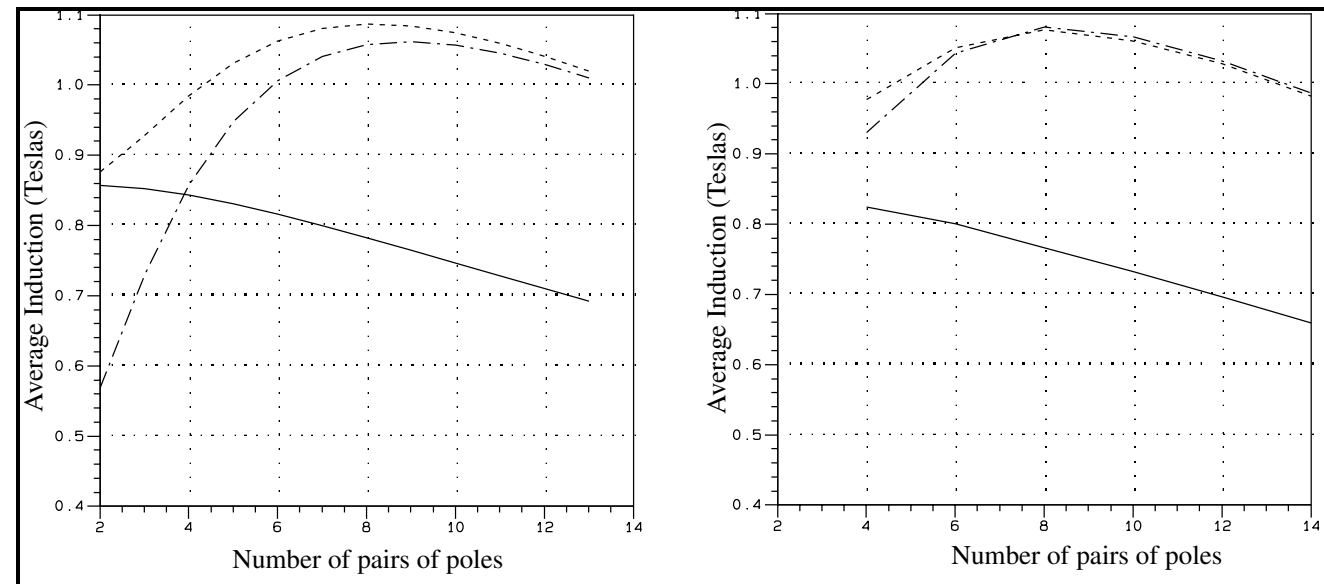

First structure

- - - Second structure

-.... Third structure

Fig. 4. Average Induction in front of the center of a pole.

The calculation time necessary to compute the data of the 3 curves of the first graph of Fig. 4 (36 computations) is only around 30 seconds in a Pentium IV $1.6 \mathrm{GHz}$ using Linux.

To validate the semi-analytical method results, the average induction in front of the center of the pole has also been calculated with a nodal Finite Element code (Flux3D) using a scalar potential formulation. This calculation has been done for the same set of dimensions as the results obtained with the semianalytical method. The values of the average induction are given in the second graph of Fig. 4 as functions of the number of pairs of poles for the 3 kinds of structure. The calculation time necessary to obtain the data is around 5 hours in a Pentium IV $1.6 \mathrm{Ghz}$ using Windows XP. It can be noted that the presented results are in good accordance with the semi-analytical method ones.

This FE study allows us to validate the presented method. It can be seen that the semi-analytical method results are nearest to those obtained by FE method for iron rotor cores cases than for ironless rotor cases. This is because in ironless case the leakage fluxes are more important, so the FE mesh must be very fine in all the study domain to obtain a good accuracy of the results.

\section{Conclusion}

In this paper a study of 3 kinds of discoidal PM machine is presented. The field calculation in the device is done using a semi analytical method based on the magnetic charges theory. This method is compared in the studied cases with the classical Nodal Finite Element method. This way of calculation appears to be a very fast and efficient tool for the design of such devices. The presented results underscore the interest of the use of Halbach array in discoidal PM machines.

\section{References}

1] F. Profumo, Z. Zhang and A. Tenconi, Axial flux machines drives: a new viable solution for electric cars, IEEE Trans. on Ind. Electr., 44(1) (Feb 1997), 39-45.

2] F. Caricchi, F. Crescimbini and O. Honrati, Modular axial-flux permanent-magnet motor for ship propulsion drives, IEEE Transactions on Energy Conversion 14(3) (Sep 1999), 673-679.

3] T.S. El-Hasan and P.C.K. Luk, Magnet topology optimization to reduce harmonics in High speed axial flux generators. IEEE Transactions on Magnetics 39(5) (Sep 2003) 3340-3342 
4] J.F. Charpentier and G. Lemarquand, Calculation of ironless PM couplings using semi-numerical magnetic pole theory method, Compel 20(1) (2001), 72-89.

5] K. Halbach, Design of permanent multipole magnets with oriented RE Cobalt material, Nucl. Inst. and Meth. 169 (1980), $1-10$.

6] Z.Q. Zhu, Z.P. Xia, Y.F. Shi, D. Howe, A. Pride and X.J. Chan, Performance of Halabach magnetized Brushless AC Motor, IEEE Transactions on Magnetics 39(5) (Sep 2003), 2992-2994.

77] TNL Patterson, On Gauss and Labotto based integration formulae, Math Comp. 22 (1968), 877-881. 